Virginia Commonwealth University VCU Scholars Compass

\title{
Palladium Nanoparticles Supported on Ce- Metal-Organic Framework for Efficient CO Oxidation and Low-Temperature CO2 Capture
}

Andrew Lin

Virginia Commonwealth University

Amr Awad Ibrahim

Virginia Commonwealth University

Pezhman Arab

Virginia Commonwealth University

Hanii M. El-Kaderi

Virginia Commonwealth University

M. Samy El-Shall

Virginia Commonwealth University, mselshal@vcu.edu

Follow this and additional works at: http://scholarscompass.vcu.edu/chem_pubs

Part of the Chemistry Commons

(C) 2017 American Chemical Society

\section{Downloaded from}

http://scholarscompass.vcu.edu/chem_pubs/82

This Article is brought to you for free and open access by the Dept. of Chemistry at VCU Scholars Compass. It has been accepted for inclusion in Chemistry Publications by an authorized administrator of VCU Scholars Compass. For more information, please contact libcompass@vcu.edu. 


\title{
Palladium Nanoparticles Supported on Ce-Metal-Organic Framework for Efficient CO Oxidation and Low-Temperature $\mathrm{CO}_{2}$ Capture
}

\author{
Andrew Lin, ${ }^{\dagger}$ Amr Awad Ibrahim, ${ }^{\dagger \dagger}$ Pezhman Arab, ${ }^{\dagger}$ Hani M. El-Kaderi, ${ }^{\dagger}$ and M. Samy El-Shall ${ }^{*}{ }^{\dagger}$ (i) \\ ${ }^{\dagger}$ Department of Chemistry Virginia Commonwealth University Richmond, Virginia 23284-2006, United States \\ ${ }^{*}$ Department of Chemistry, Faculty of Science, Mansoura University, Al-Mansoura, Egypt
}

Supporting Information

ABSTRACT: In this article, we report the lowest-temperature $\mathrm{CO}$ oxidation catalyst supported on metal-organic frameworks (MOFs). We have developed a facile, general, and effective approach based on microwave irradiation for the incorporation of Pd nanoparticle catalyst within Ce-MOF. The resulting Pd/ $\mathrm{Ce}-\mathrm{MOF}$ material is a unique catalyst that is capable of $\mathrm{CO}$ oxidation at modest temperatures and also of efficient uptake of the product $\mathrm{CO}_{2}$ gas at low temperatures. The observed catalytic activity of this material toward $\mathrm{CO}$ oxidation is significantly higher than those of other reported metal

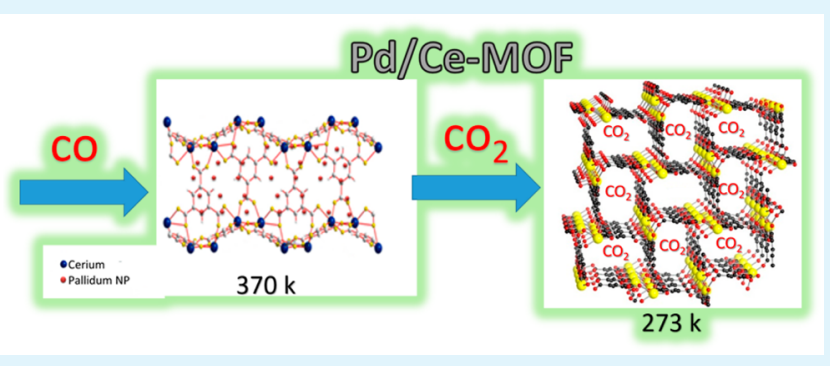
nanoparticles supported on MOFs. The high activity of the $\mathrm{Pd} / \mathrm{Ce}-\mathrm{MOF}$ catalyst is due to the presence of $\mathrm{Ce}(\mathrm{III})$ and $\mathrm{Ce}(\mathrm{IV})$ ions within the metal-organic framework support. The Pd nanoparticles supported on the Ce-MOF store oxygen in the form of a thin palladium oxide layer at the particle-support interface, in addition to the oxygen stored on the $\mathrm{Ce}(\mathrm{III}) / \mathrm{Ce}$ (IV) centers. Oxygen from these reservoirs can be released during $\mathrm{CO}$ oxidation at $373 \mathrm{~K}$. At lower temperatures $(273 \mathrm{~K})$, the $\mathrm{Pd} / \mathrm{Ce}-$ MOF has a significant $\mathrm{CO}_{2}$ uptake of $3.5 \mathrm{mmol} / \mathrm{g}$.

KEYWORDS: palladium nanoparticles, cerium-MOF, $\mathrm{CO}$ oxidation, $\mathrm{CO}_{2}$ uptake, heterogeneous catalysis, Pd catalyst supported on Ce-MOF

\section{INTRODUCTION}

Metal-organic frameworks (MOFs) are a new class of highly porous crystalline materials with well-defined cavities or channels that can accommodate a variety of guest species of different sizes and shapes for a variety of applications in gas storage, separations, and heterogeneous catalysis. ${ }^{1-6}$ The interest in MOFs as catalyst supports arises from their unusually large surface areas, well-ordered crystalline structures, high porosities, tunable pore sizes, and modifiable surface properties. $^{1-6}$ MOFs provide several ways to incorporate catalysts through their centers with unsaturated coordination sites, metal nanoparticles encapsulated within the pores, and catalytic sites inherent in the structures of the frameworks. ${ }^{1-6}$

The catalytic activities of several MOF-based catalysts have been demonstrated for liquid-phase reactions such as cyanosilylation, hydrogenation, polymerization, and isomerization, $^{7-10}$ as well as for enantioselective separations, organic transformations for the production of chemicals, ${ }^{11,12}$ oxygen reduction reactions in fuel cells, ${ }^{13,14}$ and photocatalytic hydrogen production. ${ }^{13,15,16}$ In contrast to liquid-phase reactions, only a few gas-phase reactions and gas-solid reactions using MOF-based catalysts have been investigated. For example, a few reports exist on the use of MOF-based catalysts for $\mathrm{CO}$ oxidation. ${ }^{3,4,17-21}$ This reaction has significant health, industrial, and environmental impacts because of the toxicity of $\mathrm{CO}^{22}$ and the need to remove it from indoor air and from the $\mathrm{H}_{2}$ streams used for the fuel-cell applications because of its poisoning effect on the performance of fuel cells. ${ }^{23}$ Although catalytic oxidation is considered to be the most effective method for the removal of $\mathrm{CO}$, the generation of $\mathrm{CO}_{2}$ creates another serious concern, given that $\mathrm{CO}_{2}$ capture and sequestration (CCS) remains a central technique for mitigating global warming and climate changes. Therefore, the development of low-temperature $\mathrm{CO}$ oxidation catalysts that are also capable of efficient $\mathrm{CO}_{2}$ capture is of immense interest for a variety of applications such as improving fuel-cell performance, removing toxic gases released into the atmosphere by combustion and automotive exhaust processes, and meeting stringent environmental regulations for the treatment of air pollutants. $^{24-26}$

In this article, we report on the development of an MOFbased catalyst that exhibits synergetic effects in the oxidation of $\mathrm{CO}$ at moderate temperatures and the capture of $\mathrm{CO}_{2}$ at low temperatures. The design strategy for this catalyst was based on the hypothesis that a cerium-based MOF could have a high affinity for oxygen because of the presence of cerium $f$ orbitals

Received: March 13, 2017

Accepted: May 9, 2017

Published: May 9, 2017 
and could be able to store oxygen and enhance the catalytic oxidization of $\mathrm{CO}$ by $\mathrm{Pd}$ nanoparticles. The Ce-based MOF chosen for this study, namely, $\left\{\left[\mathrm{Ce}(\mathrm{BTC})\left(\mathrm{H}_{2} \mathrm{O}\right)\right] \cdot \mathrm{DMF}\right\}_{n}$ (where BTC is benzene-1,3,5-tricarboxylate and DMF is dimethylformamide), has a polymeric structure formed by the assembly of cerium metal clusters using the BTC as an organic linker. $^{27}$ The structure is marked by highly dense and homogeneously distributed cerium sites. The high affinity of these sites for oxygen provides an excellent opportunity to deposit an active $\mathrm{CO}$ oxidation catalyst such as $\mathrm{Pd}$ nanoparticles in regions where where $\mathrm{CO}$ molecules can be efficiently adsorbed.

Our approach to the synthesis of $\mathrm{Pd} / \mathrm{Ce}-\mathrm{MOF}$ is based on the simultaneous activation of the pores of the Ce-MOF and the rapid chemical reduction of the $\mathrm{Pd}$ precursor, namely, $\mathrm{Pd}\left(\mathrm{NO}_{3}\right)_{2}$. This can be achieved by the fast microwaveirradiation- (MWI-) assisted chemical reduction of the Pd ions using hydrazine hydrate as a reducing agent. The main advantage of MWI over other conventional heating methods is the rapid and uniform heating of the reaction mixture, which results in the fast reduction of the $\mathrm{Pd}$ ions with the simultaneous generation of a supersaturated solution of $\mathrm{Pd}$ atoms and the subsequent nucleation and growth of these atoms to form Pd nanoparticles within the pores and on the surface of the Ce-MOF crystals. ${ }^{4,24,26,28,29}$ Furthermore, MWI heating can remove the coordinated DMF molecules around the Ce centers of the Ce-MOF crystals, thus generating a higher surface area and accessible pores for catalytic processes. $^{29}$

\section{RESULTS AND DISCUSSION}

The as-prepared Ce-MOF crystals were obtained by filtration from the reaction mixture, washed with ethanol, and dried in a vacuum oven at $100{ }^{\circ} \mathrm{C}$ as colorless needle-shaped crystals. The XRD pattern of the Ce-MOF displayed in Figure 1 shows the

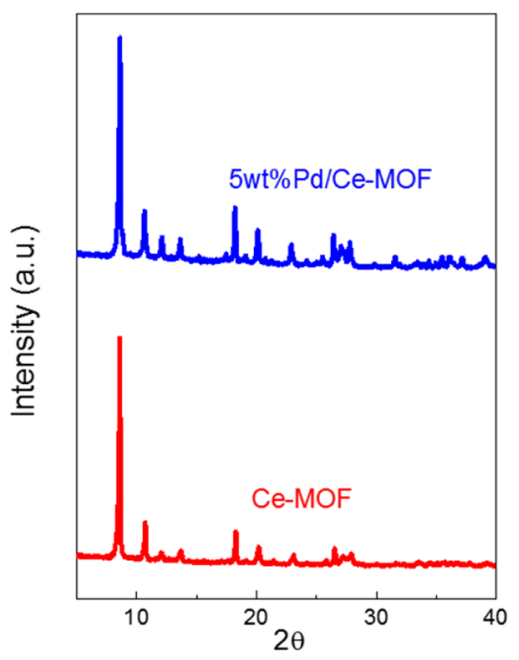

Figure 1. XRD patterns of Ce-MOF and 5 wt \% Pd Ce-MOF.

characteristic peaks at $(2 \theta) 8.4^{\circ}, 10.6^{\circ}$, and $18.1^{\circ}$, indicating a high degree of crystallinity, in excellent agreement with the literature results. ${ }^{30}$ The actual loading of the Pd nanoparticles on the Ce-MOF was determined by inductively coupled plasma mass spectrometry (ICP-MS) to be $4.93 \mathrm{wt} \%$, in excellent agreement with the nominal loading of 5 wt \% used in the preparation of the sample with the XRD pattern displayed in
Figure 1. The XRD pattern indicates that the incorporation of the Pd nanoparticles within the Ce-MOF crystals creates a supported catalyst without compromising the integrity of the Ce-MOF crystal structure. ${ }^{30}$

The Fourier transform infrared (FTIR) spectrum of the as prepared Ce-MOF crystals is presented in Figure 2. The spectrum shows the characteristic bands of the $\mathrm{COO}^{-}$groups of $\mathrm{BTC}^{3-}$, such as the $1612 \mathrm{~cm}^{-1}$ asymmetric vibration and the 1435 and $1373 \mathrm{~cm}^{-1}$ symmetric vibrations. In addition, lowintensity bands of the $\mathrm{Ce}-\mathrm{O}$ stretching vibrations can be observed near $500-700 \mathrm{~cm}^{-1}$. Also, the presence of DMF in the Ce-MOF crystals is evident from the band for $\mathrm{C}=\mathrm{O}$ vibrations at $1666 \mathrm{~cm}^{-1}$, indicating that the framework is stabilized by the presence of the strongly adsorbed solvent molecules. The strong $\mathrm{OH}$ stretching band of water at 3450 $\mathrm{cm}^{-1}$ is attributed to physically adsorbed water molecules on the surface of the Ce-MOF crystals.

The Raman spectrum of the Ce-MOF crystals is displayed in Figure $2 \mathrm{~b}$. The spectrum clearly shows the five characteristic sharp Raman bands at 826, 1006, 1450, 1550, and $1610 \mathrm{~cm}^{-1}$ assigned to out-of-plane ring $\mathrm{C}-\mathrm{H}$ bending vibrations, $\mathrm{C}=\mathrm{C}$ modes of the benzene ring, $\nu_{\text {sym }}$ of the $\mathrm{C}-\mathrm{O}_{2}$ units, $\nu_{\text {asym }}$ of the $\mathrm{C}-\mathrm{O}_{2}$ units, and $\mathrm{C}=\mathrm{C}$ modes of the benzene ring, respectively, in agreement with the assignments reported in the literature. ${ }^{31}$

The morphology of the supported catalysts was characterized by transmission electron microscopy (TEM). It can be seen from Figure $3 \mathrm{a}, \mathrm{b}$ that the Ce-MOF crystals had needle-shaped particles that ranged in size from 2 to $6 \mu \mathrm{m}$. Figure 3c,d displays TEM images of the $5 \mathrm{wt} \% \mathrm{Pd} / \mathrm{Ce}-\mathrm{MOF}$ catalyst prepared by the microwave-assisted chemical reduction of palladium nitrate using hydrazine hydrate as the reducing agent. It is clear that this procedure resulted in the homogeneous distribution of the $\mathrm{Pd}$ nanoparticles across the Ce-MOF crystals. From the measured particle size distribution shown in Figure 3e, the $\mathrm{Pd}$ nanoparticles in the 5 wt \% Pd/Ce-MOF catalyst had an average size of $4.6 \pm 2.2 \mathrm{~nm}$, which suggests that most of the particles were present on the surface of the Ce-MOF crystals.

To characterize the surface compositions of the Ce-MOF and the supported Pd catalysts, we carried out XPS measurements, as shown in Figure 4 for both the Pd $3 d$ and Ce $3 d$ electrons. The C 1s XPS spectra of the Ce-MOF support and the 5 wt \% Pd/Ce-MOF catalyst are shown in Figure S1 (Supporting Information). The C 1s spectra show peaks corresponding to oxygen-containing groups between 285.5 and $289 \mathrm{eV}$, in addition to $\mathrm{sp}^{2}$-bonded carbon $\mathrm{C}=\mathrm{C}$ at $284.5 \mathrm{eV}$. Typically, peaks at 285.6, 286.7, 287.7, and $289 \mathrm{eV}$ are assigned to the $\mathrm{C} 1 \mathrm{~s}$ signals of $\mathrm{C}-\mathrm{OH}, \mathrm{C}-\mathrm{O}, \mathrm{C}=\mathrm{O}$, and $\mathrm{HO}-\mathrm{C}=\mathrm{O}$ groups, respectively. ${ }^{29}$ The Ce $3 \mathrm{~d}$ spectra of both the Ce-MOF support and the $5 \mathrm{wt} \% \mathrm{Pd} / \mathrm{Ce}-\mathrm{MOF}$ supported catalyst show the presence of the $\mathrm{Ce}^{4+} 3 \mathrm{~d}$ level characterized by four peaks corresponding to $\mathrm{v}$ and $\mathrm{v}^{\prime}\left(3 \mathrm{~d}^{5 / 2}\right)(882.1$ and $888.7 \mathrm{eV}$, respectively) and $\mathrm{u}$ and $\mathrm{u}^{\prime}\left(3 \mathrm{~d}^{3 / 2}\right)$ (900.4 and $906.7 \mathrm{eV}$, respectively). ${ }^{32}$ We also observed two peaks (doublet) at 885 and $904.1 \mathrm{eV}$, corresponding to $\mathrm{v}^{\prime}$ and $\mathrm{u}^{\prime}$, respectively, for $\mathrm{Ce}^{3+}$ $3 \mathrm{~d}$ states. $^{33}$ The XPS spectra of the Pd 3d electron in the $5 \mathrm{wt}$ $\% \mathrm{Pd} / \mathrm{Ce}-\mathrm{MOF}$ catalyst show binding energies of 335.8 and $340.1 \mathrm{eV}$, indicating that the atomic-percentage ratio of $\mathrm{Pd}^{0}$ to $\mathrm{Pd}^{2+}$ in the $5 \mathrm{wt} \% \mathrm{Pd} / \mathrm{Ce}-\mathrm{MOF}$ was $1.37 .^{29}$ The presence of $\mathrm{Pd}^{2+}$ is attributed to the formation of a thin layer of $\mathrm{PdO}$, which can act as a reservoir for oxygen that can be released during the $\mathrm{CO}$ oxidation reaction. 

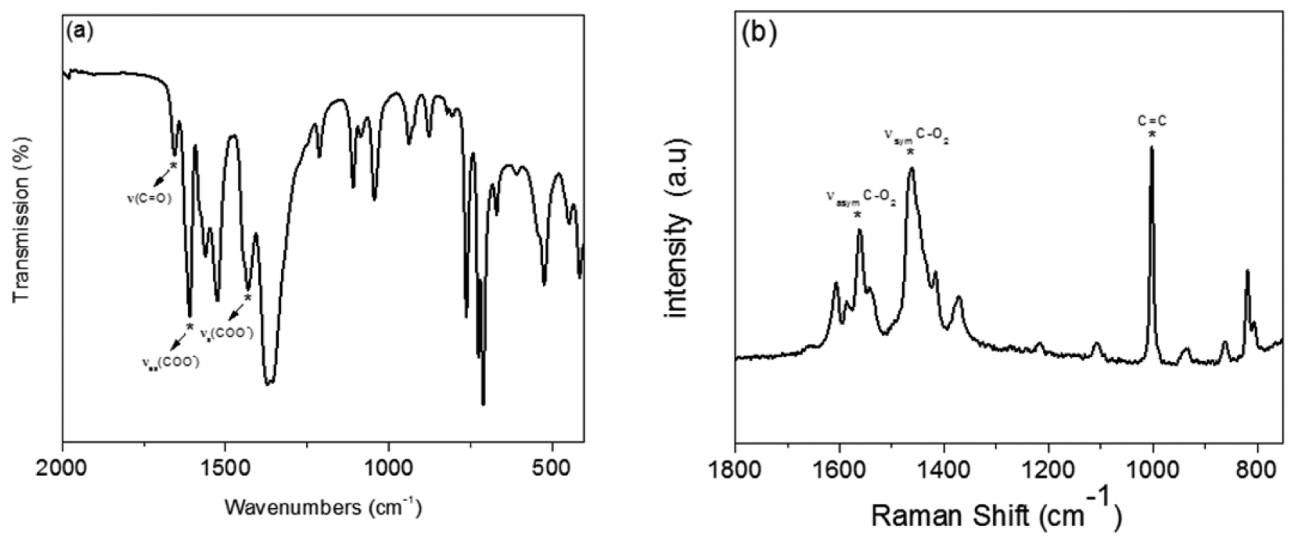

Figure 2. (a) FTIR and (b) Raman spectra of Ce-MOF.
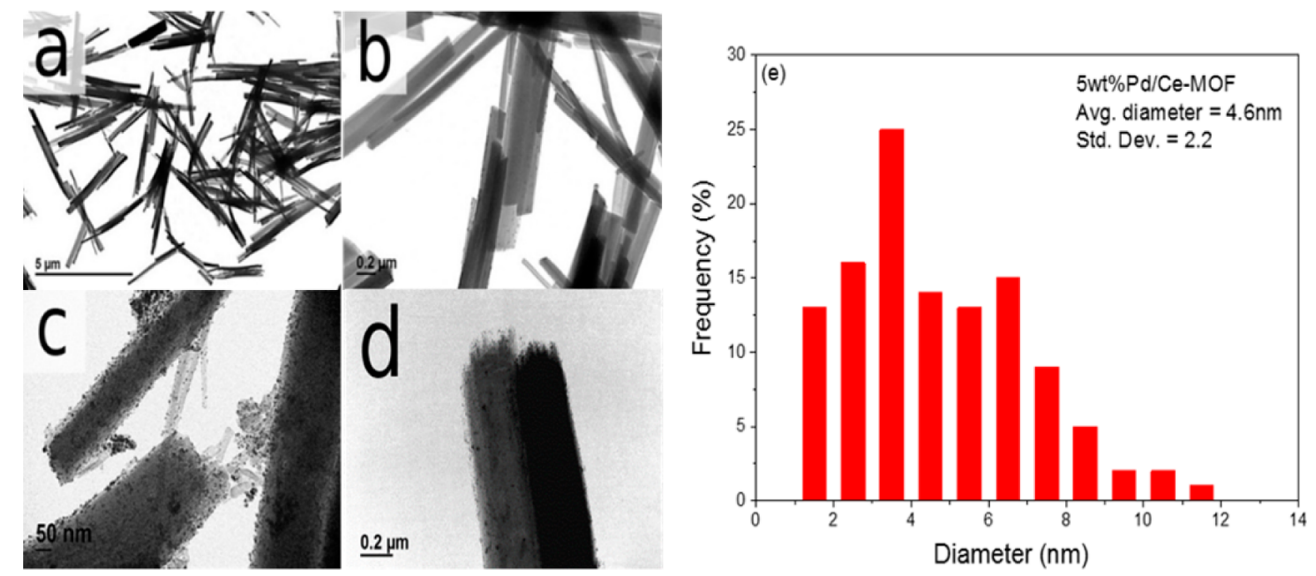

Figure 3. TEM images of (a,b) Ce-MOF crystals and (c,d) 5 wt \% Pd/Ce-MOF catalyst. (e) Size distribution of the Pd nanoparticles in the 5 wt \% $\mathrm{Pd} / \mathrm{Ce}-\mathrm{MOF}$ catalyst.
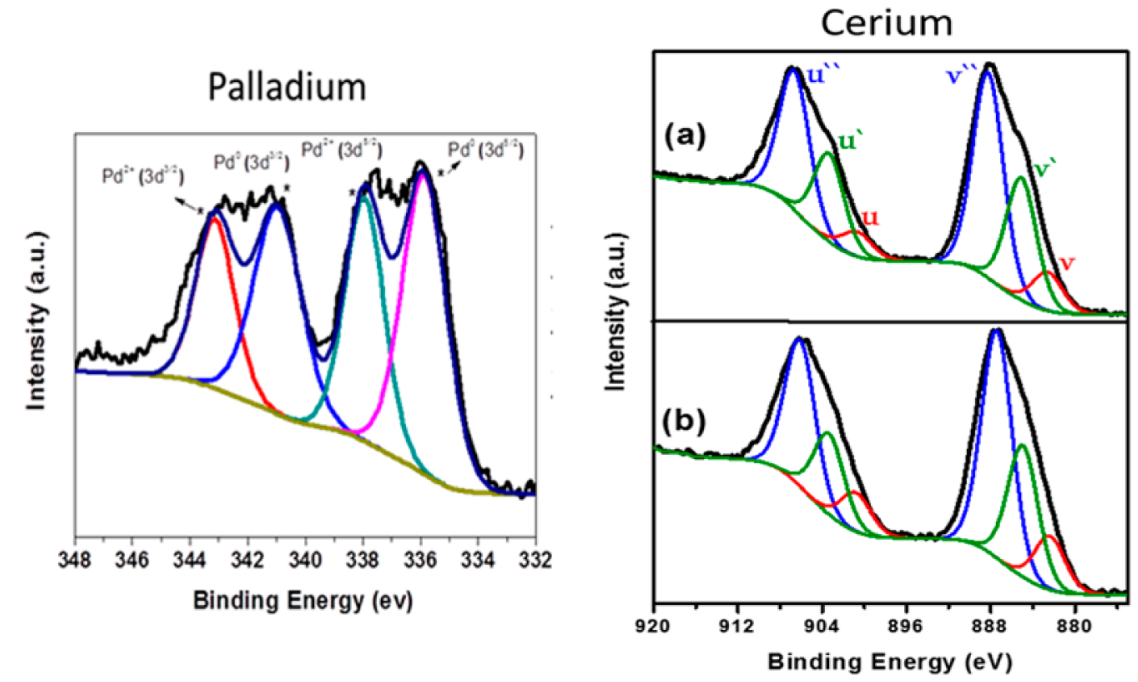

Figure 4. XPS spectra of (left) Pd 3d electrons in 5 wt \% Pd/Ce-MOF catalyst and (right) Ce 3d electrons in (a) Ce-MOF and (b) 5 wt \% Pd/CeMOF catalyst.

The thermal stability of the Ce-MOF was characterized by thermogravimetric analysis (TGA) in air, the results of which are shown in Figure 5. The TGA curve for the Ce-MOF is consistent with the literature results and shows the loss of adsorbed water and DMF over the temperature range of 150$250{ }^{\circ} \mathrm{C}$, followed by framework decomposition at $\sim 350{ }^{\circ} \mathrm{C} .{ }^{27}$ On the other hand, the TGA trace for the as-prepared 5 wt \%
Pd/Ce-MOF catalyst shows only an initial weight loss of $\sim 15$ wt $\%$ due to water desorption at about $100{ }^{\circ} \mathrm{C}$ and significant catalyst decomposition at $500{ }^{\circ} \mathrm{C}$. The TGA trace of the 5 wt $\%$ $\mathrm{Pd} / \mathrm{Ce}-\mathrm{MOF}$ catalyst indicates that the Pd loading process under MWI eliminates DMF from the pores of the Ce-MOF through exchange with water. It also suggests that the small $\mathrm{Pd}$ nanoparticles incorporated within the pores of the Ce-MOF 


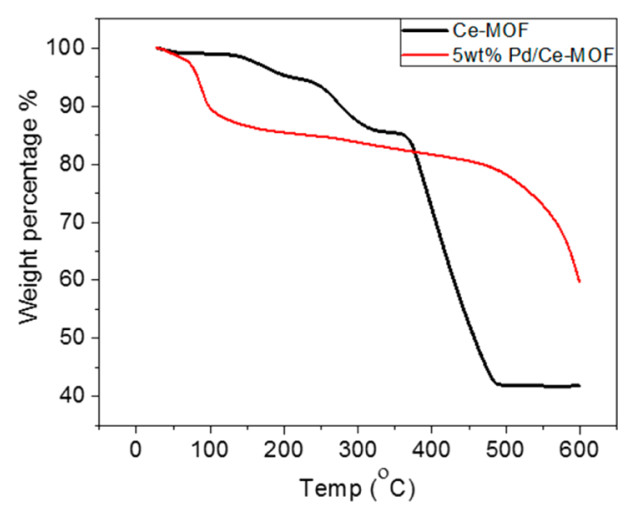

Figure 5. Comparison of the TGA plots of Ce-MOF and 5 wt \% Pd/ Ce-MOF.

provide an extra stabilizing effect against the collapse of the framework, as is evident by the significant increase in the decomposition temperature from $\sim 350$ to $500{ }^{\circ} \mathrm{C}$.

The $\mathrm{N}_{2}$ gas sorption isotherms at $-196{ }^{\circ} \mathrm{C}$, shown in Figure $6 \mathrm{a}$, reveal that the Ce-MOF had a small Brunauer-EmmettTeller (BET) specific surface area of $62 \mathrm{~m}^{2} / \mathrm{g}$, consistent with the low porosity of this MOF and with previous measurements. ${ }^{27,30}$ Interestingly, the surface area increased to $89 \mathrm{~m}^{2} / \mathrm{g}$ for the 5 wt $\% \mathrm{Pd} / \mathrm{Ce}-\mathrm{MOF}$ catalyst, indicating that the treatment of Ce-MOF under MWI during the reduction of the $\mathrm{Pd}$ ions by hydrazine hydrate resulted in the activation of the Ce-MOF, probably by removing impurities and unwanted species from the surface and pores of the MOF.

We considered the impact of loading Pd onto the Ce-MOF on the $\mathrm{CO}_{2}$ uptake because of the contribution of $\mathrm{CO}_{2}$ to global warming and because of its potential use as chemical feedstock. It has been observed that the loading of porous structures such as MOFs and high-surface-area graphite plates with Pd nanoparticles can have adverse effects on the gas uptake of these structures, which is very important for gas storage and separation, as well as for use in catalytic processes. ${ }^{34}$ For example, it has been reported that the loading of a redox-active MOF with $\mathrm{Pd}$ nanoparticles resulted in an improvement in the hydrogen storage of the MOF but had the opposite effect on its $\mathrm{CO}_{2}$ capture. ${ }^{33}$ Whereas Pd nanoparticles provide effective sites for improved hydrogen interactions, the presence of other species such as counterions inside the pores of MOFs has been suggested to impede $\mathrm{CO}_{2}$ uptake. ${ }^{35,36}$

The loading of Pd onto Ce-MOF (5 wt \%) was found to lead to a significant improvement in the $\mathrm{CO}_{2}$ uptake at $273 \mathrm{~K}$, as shown in Figure 6b. Table 1 reports the BET surface area and $\mathrm{CO}_{2}$ uptake results for Ce-MOF and 5 wt \% Pd/Ce-MOF.

Table 1. BET Surface Areas and $\mathrm{CO}_{2}$ Uptakes at $273 \mathrm{~K}$ of Ce-MOF and 5 wt \% Pd/Ce-MOF

$\begin{array}{lcc}\text { material } & \begin{array}{c}\mathrm{BET} \text { surface area } \\ \left(\mathrm{m}^{2} \mathrm{~g}^{-1}\right)\end{array} & \begin{array}{c}\mathrm{CO}_{2} \text { uptake } \\ \left(\mathrm{mmol} \mathrm{g}^{-1}\right)\end{array} \\ \text { Ce-MOF } & 62.2^{a}\left(636^{b}\right) & 1.7 \\ 5 \mathrm{wt} \% \mathrm{Pd} / \mathrm{Ce}-\mathrm{MOF} & 89.3^{a}\left(620^{b}\right) & 3.5\end{array}$

${ }^{a}$ Calculated from $\mathrm{N}_{2}$ isotherms. ${ }^{b}$ Obtained from $\mathrm{CO}_{2}$ adsorption isotherms.

Whereas the pristine Ce-MOF had an uptake of only $1.7 \mathrm{mmol}$ $\mathrm{g}^{-1}$ at 1.0 bar, the 5 wt \% Pd/Ce-MOF exhibited an improved $\mathrm{CO}_{2}$ capture capacity that reached $3.5 \mathrm{mmol} \mathrm{g}^{-1}$ under the same conditions. As can be seen in Figure $6 b$, the fully reversible $\mathrm{CO}_{2}$ isotherm of Ce-MOF shows a pronounced hysteresis, which is most likely due to the fact that the ultranarrow pores of Ce-MOF have a strong affinity for $\mathrm{CO}_{2}$ molecules yet only limited adsorption sites because of the low surface area of this MOF. On the other hand, loading of $\mathrm{Pd}$ onto Ce-MOF and its subsequent activation increased the surface area from $62 \mathrm{~m}^{2} / \mathrm{g}$ for Ce-MOF to $89 \mathrm{~m}^{2} / \mathrm{g}$ for the $5 \mathrm{wt}$ $\% \mathrm{Pd} / \mathrm{Ce}-\mathrm{MOF}$ and presumably provided additional adsorption sites for $\mathrm{CO}_{2}$ on the surface of the $\mathrm{Pd}$ nanoparticles, as evidenced by the improved $\mathrm{CO}_{2}$ uptake of 5 wt \% Pd/Ce-MOF reported in Table 1 and the diminished hysteresis of the $\mathrm{CO}_{2}$ isotherm of 5 wt \% Pd/Ce-MOF shown in Figure $6 \mathrm{~b}$.

Despite their low $\mathrm{N}_{2}$ uptakes at $77 \mathrm{~K}$, Ce-MOF crystals show high $\mathrm{CO}_{2}$ uptake values at $273 \mathrm{~K}$, which is indicative of their microporosity. ${ }^{37}$ The poor $\mathrm{N}_{2}$ adsorption of the Ce-MOF can be attributed to the low diffusivity and adsorption kinetics of $\mathrm{N}_{2}$ molecules at $77 \mathrm{~K}$, which is due to the ultranarrow pores of the Ce-MOF. ${ }^{37,38}$ Because of the substantial $\mathrm{CO}_{2}$ uptake by ultramicroporous materials, the use of $\mathrm{CO}_{2}$ as a probe for porosity measurements is preferred over the use of $\mathrm{N}_{2}{ }^{37}$ Accordingly, we calculated the pore size distribution and surface area of the Ce-MOF using $\mathrm{CO}_{2}$ adsorption isotherms collected at $273 \mathrm{~K}$. As expected, our $\mathrm{CO}_{2}$-based porosity measurements indicated a much higher surface area and smaller pores for the Ce-MOF when compared to our $\mathrm{N}_{2}$-based porosity measurements, as shown in Table 1 . It should be mentioned that the use of $\mathrm{CO}_{2}$ isotherms of materials with high binding affinities for $\mathrm{CO}_{2}$ can lead to the overestimation of surface area values. ${ }^{39}$ We also estimated the pore size distribution for $5 \mathrm{wt} \% \mathrm{Pd} / \mathrm{Ce}-\mathrm{MOF}$ using nonlocal density
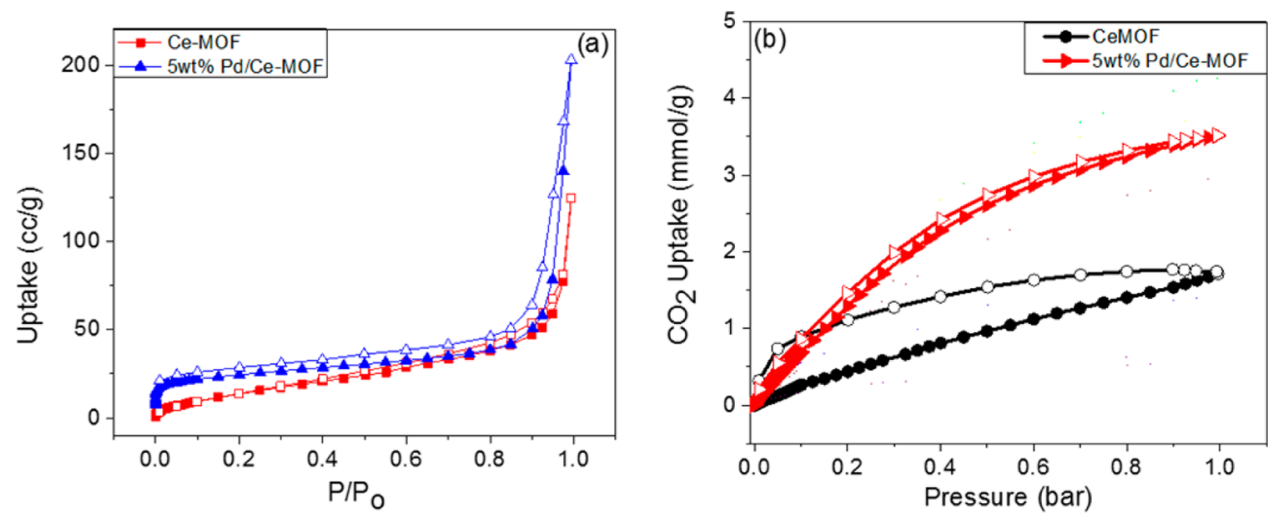

Figure 6. (a) $\mathrm{N}_{2}$ gas sorption isotherms and (b) $\mathrm{CO}_{2}$ uptakes of Ce-MOF and 5 wt \% Pd/Ce-MOF. 
functional theory (NLDFT) ${ }^{39}$ with both the $\mathrm{N}_{2}(7.3 \AA)$ and $\mathrm{CO}_{2}(5.4 \AA)$ isotherms (Figure S2, Supporting Information), and in both cases, the pore size distribution values were in good agreement with reported channel dimensions of the Ce-MOF $(6.6 \times 6.6 \AA) .{ }^{27}$ The ability of the Ce-MOF to bind and release $\mathrm{CO}_{2}$ during catalytic processes is very important to ensure sufficient mass transfer inside the pores. Later in this section, we demonstrate the remarkable activity of the $5 \mathrm{wt} \% \mathrm{Pd} / \mathrm{Ce}$ $\mathrm{MOF}$ in the low-temperature oxidation of $\mathrm{CO}$ to $\mathrm{CO}_{2}$.

The CO oxidation conversions for different $\mathrm{Pd}$ loadings incorporated within the Ce-MOF are shown in Figure 7. The

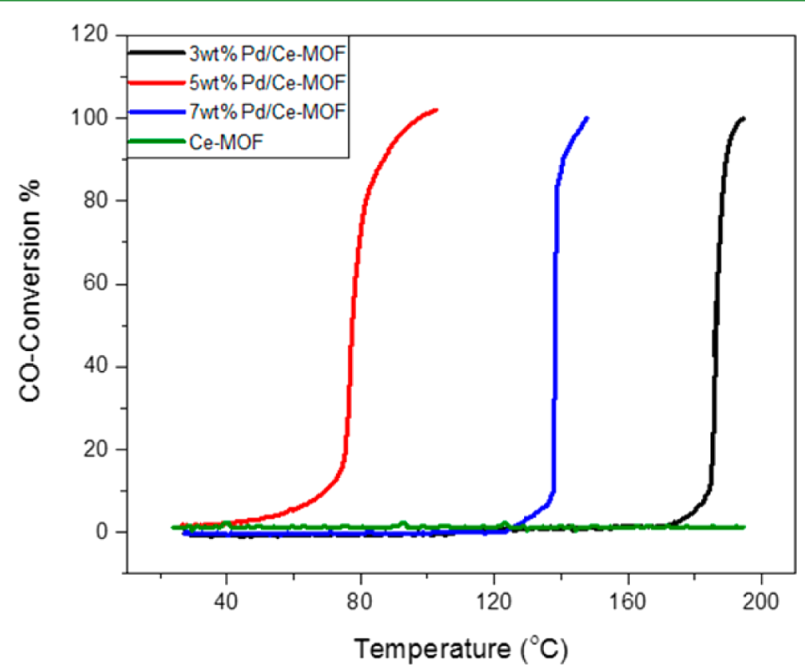

Figure 7. CO oxidation with different loadings of $\mathrm{Pd}$ as a function of temperature for a reactant gas mixture containing $4.0 \mathrm{wt} \% \mathrm{CO}$ and $20.0 \mathrm{wt} \% \mathrm{O}_{2}$ in helium ( $25 \mathrm{mg}$ of catalyst, flow rate of $100 \mathrm{~cm}^{3} / \mathrm{min}$ ).

CO oxidation conversion increased significantly as the $\mathrm{Pd}$ content was increased from 3 wt \%, at which the 50\% and $100 \%$ conversions occurred at 180 and $190{ }^{\circ} \mathrm{C}$, respectively, to $5 \mathrm{wt}$ $\%$, at which these conversions occur at 77 and $92{ }^{\circ} \mathrm{C}$, respectively. However, increasing the Pd loading to 7 wt \% resulted in increasing the temperatures of the 50\% and $100 \%$ conversion to 140 and $148{ }^{\circ} \mathrm{C}$, respectively. This is probably due to the aggregation of the Pd nanoparticles on the surface of the Ce-MOF, which could result in a decrease of the surface area of the catalyst. It should also be noted that the Ce-MOF with no loading of $\mathrm{Pd}$ nanoparticles shows no activity for $\mathrm{CO}$ oxidation at temperatures below $200{ }^{\circ} \mathrm{C}$. This confirms that the $\mathrm{Pd}$ nanoparticles supported on the Ce-MOF play the primary role in the oxidation process. The ability of cerium to store oxygen appears to enhance the oxidation process by creating oxygen vacancies, leading to enhanced activity.

We also considered loading the Ce-MOF with other metal nanoparticle catalysts such as Au and Pt using the same MWIassisted chemical reduction procedure as used for the preparation of the $\mathrm{Pd} / \mathrm{Ce}-\mathrm{MOF}$ catalyst. Comparison of the oxidations of $\mathrm{CO}$ conducted on Ce-MOFs with 5 wt \% loadings of $\mathrm{Pd}, \mathrm{Au}$, and $\mathrm{Pt}$ nanoparticles (Figure S3, Supporting Information) indicates that the $5 \mathrm{wt} \% \mathrm{Pd} / \mathrm{Ce}-\mathrm{MOF}$ catalyst had the highest activity for $\mathrm{CO}$ oxidation. This could be due to the larger particle size and significant degrees of agglomeration of the $\mathrm{Au}$ and $\mathrm{Pt}$ catalysts prepared by the MWI method. The optimization of the synthesis procedures and loadings for the $\mathrm{Au} / \mathrm{Ce}-\mathrm{MOF}$ and $\mathrm{Pt} / \mathrm{Ce}-\mathrm{MOF}$ catalysts to obtain well- dispersed small-nanoparticle catalysts for CO oxidation will be published elsewhere. ${ }^{40}$

Another attractive feature of the current $\mathrm{Pd} / \mathrm{Ce}-\mathrm{MOF}$ catalyst includes the long-term activity and stability of the catalyst, as no reduction in activity was observed after several repeated catalytic reaction cycles. Figure S4 (Supporting Information) shows no decrease in the $100 \% \mathrm{CO}$ conversion provided by the 5 wt $\% \mathrm{Pd} / \mathrm{Ce}-\mathrm{MOF}$ at $90{ }^{\circ} \mathrm{C}$ over a period of 8 h.

Comparison of the $\mathrm{CO}$ oxidation activity of the $5 \mathrm{wt} \% \mathrm{Pd} /$ Ce-MOF with those of other nanoparticle catalysts supported on MOFs demonstrates the remarkable activity of the $\mathrm{Pd} / \mathrm{Ce}$ MOF supported catalyst. For example, a 5 wt \% Au nanoparticle catalyst $(4.2 \mathrm{~nm})$ supported on ZIF-8 showed $50 \% \mathrm{CO}$ conversion at $170{ }^{\circ} \mathrm{C}$ in comparison with $77^{\circ} \mathrm{C}$ for the current 5 wt \% Pd/Ce-MOF. ${ }^{3}$ This significant difference in reactivity is even more remarkable when comparing the large surface area of ZIF-8 $\left(1413 \mathrm{~m}^{2} / \mathrm{g}\right)^{3}$ to the much smaller value of $62 \mathrm{~m}^{2} / \mathrm{g}$ for the current Ce-MOF support. This comparison clearly indicates that the enhanced activity of the $\mathrm{Pd} / \mathrm{Ce}-\mathrm{MOF}$ catalyst is due to the catalyst-support interaction of the $\mathrm{Pd}$ nanoparticles with the Ce centers of the support. Another piece of evidence for the specific role of the $\mathrm{Pd}-\mathrm{Ce}$ interaction in enhancing the catalytic activity of the $\mathrm{Pd} / \mathrm{Ce}-\mathrm{MOF}$ catalyst comes from comparing the activity of the 1 wt $\% \mathrm{Pd}$ catalyst supported on the MOF compound $\mathrm{Cu}_{3}(\mathrm{BTC})_{2}$ with that of the current 5 wt $\% \mathrm{Pd} / \mathrm{Ce}-\mathrm{MOF}$ catalyst. ${ }^{19}$ The temperature for $100 \% \mathrm{CO}$ conversion for the $1 \mathrm{wt} \% \mathrm{Pd} / \mathrm{Cu}_{3}(\mathrm{BTC})_{2}$ catalyst is $205{ }^{\circ} \mathrm{C}$, compared to 190 and $92{ }^{\circ} \mathrm{C}$ for the 3 wt \% Pd/CeMOF and 5 wt \% Pd/Ce-MOF, respectively, reported in this work. It should be noted that BTC is the same linker as used in the assembly of the Ce-MOF in this work, and therefore, the enhanced activity of the Pd-supported Ce-MOF appears to be more related to the $\mathrm{Pd}-\mathrm{Ce}$ interaction than to the $\mathrm{Pd}-\mathrm{BTC}$ interaction. This conclusion is also supported by the reactivity of a different metal catalyst such as the $5 \% \mathrm{Ag} / \mathrm{Cu}_{3}(\mathrm{BTC})_{2}$ catalyst, which showed $100 \% \mathrm{CO}$ conversion at $122{ }^{\circ} \mathrm{C}$ as compared to $92{ }^{\circ} \mathrm{C}$ for the $5 \mathrm{wt} \% \mathrm{Pd} / \mathrm{Ce}-\mathrm{MOF}$ catalyst. The catalyst $\mathrm{Co} / \mathrm{MOF}-74$ showed catalytic activity with $50 \% \mathrm{CO}$ conversion at $84{ }^{\circ} \mathrm{C}$ and $87 \%$ conversion at $130{ }^{\circ} \mathrm{C}$. ${ }^{41}$ However, this catalyst was unstable, and the framework collapsed after being heated above $150{ }^{\circ} \mathrm{C}$ in air and eventually transformed into $\mathrm{Co}_{3} \mathrm{O}_{4}$ at $230{ }^{\circ} \mathrm{C}$. ${ }^{41}$

Table 2 summarizes the catalytic activities for $\mathrm{CO}$ oxidation of several MOF-supported catalysts. These data clearly demonstrate that the $\mathrm{Pd} / \mathrm{Ce}-\mathrm{MOF}$ catalyst prepared in this work exhibits a unique activity for $\mathrm{CO}$ oxidation in comparison with different types of MOF-based catalysts. This unique activity is attributed to the synergy between the Pd nano-

Table 2. Comparison of CO Oxidations on Metal-Supported MOF Catalysts

\begin{tabular}{llcc} 
wt \% Metal (ref) & \multicolumn{1}{c}{ MOF } & $T_{50 \%}{ }^{a}\left({ }^{\circ} \mathrm{C}\right)$ & $T_{100 \%}{ }^{b}\left({ }^{\circ} \mathrm{C}\right)$ \\
$5 \%$ Au3 & ZIF-8 & 170 & 210 \\
$2.7 \%$ Pd21 & MIL-53 (Al) & 100 & 115 \\
$5 \%$ Ag20 & $\mathrm{Cu}_{3}(\mathrm{BTC})_{2}$ & 100 & 120 \\
$1 \%$ Pd19 & $\mathrm{Cu}_{3}(\mathrm{BTC})_{2}$ & 190 & 205 \\
$2.9 \% \mathrm{Pd} 4$ & $\mathrm{MIL}-101(\mathrm{Cr})$ & 92 & 107 \\
$5 \% \mathrm{Pd}$ (this work) & $\mathrm{Ce}-\mathrm{MOF}$ & 77 & 96
\end{tabular}

${ }^{a_{T}}$ Temperature for $50 \%$ conversion of $\mathrm{CO}$ into $\mathrm{CO}_{2} \cdot{ }^{b}$ Temperature for $100 \%$ conversion of $\mathrm{CO}$ into $\mathrm{CO}_{2}$. 
particles and the Ce sites in the Ce-MOF, which leads to an enhanced activity for $\mathrm{CO}$ oxidation. This conclusion is consistent with the improved catalytic activity for $\mathrm{CO}$ oxidation found for Ce-modified Cu-MOF HKUST-1 $\left[\mathrm{Cu}_{3}(\mathrm{BTC})_{2}\left(\mathrm{H}_{2} \mathrm{O}\right)_{3} \cdot x \mathrm{H}_{2} \mathrm{O}\right] .{ }^{42}$ However, the relatively higher activity of that catalyst (complete conversion of $\mathrm{CO}$ at $150{ }^{\circ} \mathrm{C}$ ) was attributed to the formation of $\mathrm{CuO}-\mathrm{CeO}_{2}$ catalysts, which are known to exhibit good activity for $\mathrm{CO}$ oxidation. ${ }^{43,44}$ In the present $\mathrm{Pd} / \mathrm{Ce}-\mathrm{MOF}$ system, there is no evidence for the formation of $\mathrm{CeO}_{2}$, as the XRD pattern of the spent catalyst showed that the crystalline structures of Ce-MOF was maintained after several repeated cycles of $\mathrm{CO}$ oxidation. Therefore, the high activity of the $\mathrm{Pd} / \mathrm{Ce}-\mathrm{MOF}$ catalyst is most likely due to the interaction of the $\mathrm{Pd}$ nanoparticles and the $\mathrm{Ce}$ sites within Ce-MOF. One possible explanation for this activity could be due to electron transfer from the Pd nanoparticles to the $\mathrm{Ce}^{4+}$ cations, leading to the formation of $\mathrm{Ce}^{3+}$, and subsequent electron transfer from $\mathrm{Ce}^{3+}$ to the adsorbed $\mathrm{O}_{2}$ at the $\mathrm{Pd} / \mathrm{Ce}-\mathrm{MOF}$ interface, thus promoting the formation of active oxygen species for $\mathrm{CO}$ oxidation. A similar mechanism was suggested to explain the high activity of $\mathrm{Pd} / \mathrm{CeO}_{2}$ catalysts for low-temperature $\mathrm{CO}$ oxidation. ${ }^{45}$

\section{CONCLUSIONS}

In conclusion, we have developed a facile, general, and effective approach based on microwave irradiation for the incorporation of $\mathrm{Pd}$ nanoparticle catalyst within Ce-MOF. The resulting $\mathrm{Pd} /$ Ce-MOF is a unique catalyst that is capable of both $\mathrm{CO}$ oxidation at modest temperatures $(370 \mathrm{~K})$ and efficient uptake of the product $\mathrm{CO}_{2}$ gas at low temperatures $(273 \mathrm{~K})$. The observed catalytic activity toward $\mathrm{CO}$ oxidation is significantly higher than those of other reported metal nanoparticles supported on metal-organic frameworks. The high activity of the $\mathrm{Pd} / \mathrm{Ce}-\mathrm{MOF}$ catalyst is attributed to the presence of $\mathrm{Ce}(\mathrm{III})$ and $\mathrm{Ce}(\mathrm{IV})$ ions within the metal-organic framework support. Pd nanoparticles supported on the Ce-MOF store oxygen in the form of a thin palladium oxide layer at the particle-support interface, in addition to the oxygen stored on the $\mathrm{Ce}(\mathrm{III}) / \mathrm{Ce}(\mathrm{IV})$ centers. Oxygen from these reservoirs can be released during $\mathrm{CO}$ oxidation at $373 \mathrm{~K}$. At lower temperatures $(273 \mathrm{~K})$, the $\mathrm{Pd} / \mathrm{Ce}-\mathrm{MOF}$ has a significant $\mathrm{CO}_{2}$ uptake of $3.5 \mathrm{mmol} / \mathrm{g}$. An application for the $\mathrm{Pd} / \mathrm{Ce}-\mathrm{MOF}$ material could be suggested in two separate $\mathrm{CO}$ conversion and $\mathrm{CO}_{2}$ storage devices operating at 370 and $273 \mathrm{~K}$, respectively.

\section{EXPERIMENTAL SECTION}

Starting Materials. Dimethylformamide (DMF) and ethanol were purchased from Alfa Aesar. Cerium(III) nitrate hexahydrate, trimesic acid $\left(\mathrm{H}_{3} \mathrm{BTC}\right)$, palladium(II) nitrate, and hydrazine hydrate were obtained from Sigma-Aldrich. All chemicals were used without further purification.

Synthesis of the Supported Catalysts. Synthesis of Ce-MOF was based on the following procedure: ${ }^{27}$ First, $4.04 \mathrm{~g}$ of cerium(III) nitrate hexahydrate $(10.0 \mathrm{mmol})$ and $1.40 \mathrm{~g}$ of trimesic acid (6.67 $\mathrm{mmol}$ ) were sealed into a $100 \mathrm{~mL}$ Teflon-lined hydrothermal synthesis autoclave and heated to $100{ }^{\circ} \mathrm{C}$ for $24 \mathrm{~h}$ with $60 \mathrm{~mL}$ of DMF. The resulting white crystalline powder was extracted and washed twice with hot ethanol to remove unreacted reactants and excess DMF and then dried in a vacuum oven at $100{ }^{\circ} \mathrm{C}$ for $24 \mathrm{~h}$. After recrystallization, palladium nitrate was loaded into $100 \mathrm{mg}$ of the Ce-MOF in $40 \mathrm{~mL}$ of deionized water and stirred for $1 \mathrm{~h}$. The palladium ions were reduced using hydrazine hydrate $(80 \mu \mathrm{L})$ under MWI using a $700 \mathrm{~W}$ microwave oven for $90 \mathrm{~s}$ (in 10-s intervals). The supported catalyst was washed twice with $40 \mathrm{~mL}$ of ethanol and then dried in a vacuum oven at $100{ }^{\circ} \mathrm{C}$ for $24 \mathrm{~h}$.

Characterization of the Catalysts. The crystallinity of the catalysts was characterized by powder X-ray diffraction (XRD) using an X'Pert Philips materials research diffractometer. The patterns were obtained using copper radiation $(\mathrm{Cu} \mathrm{K} \alpha, \lambda=1.5405 \AA)$ with a second monochromator at $45 \mathrm{kV}$ and $40 \mathrm{~mA}$ at a scanning speed of $2^{\circ}(2 \theta) /$ $\mathrm{min}$. FTIR spectra of calcined samples were obtained using a NicoletNexus 670 FTIR spectrophotometer $\left(4 \mathrm{~cm}^{-1}\right.$ resolution and 32 scans) in dried $\mathrm{KBr}$ (Sigma) pellets over a measuring range of 400-4000 $\mathrm{cm}^{-1}$. Raman spectra were obtained using the Thermo Scientific DXR SmartRaman instrument with a 532-nm excitation wavelength. Transmission electron microscopy (TEM) images were obtained using a JEOL JEM-1230 microscope operated at $120 \mathrm{kV}$. For TEM images, the sample powder was dispersed in methanol using ultrasonic radiation for $10 \mathrm{~min}$, and a drop of the suspension was placed onto a carbon-coated grid for TEM imaging. Gas sorption experiments were performed using a Quantachrome Autosorb iQ volumetric analyzer with adsorbates of ultrahigh-purity (UHP) grade. In a typical experiment, a sample of polymer $(\sim 50 \mathrm{mg})$ was loaded into a 9-mm large bulb cell (Quantachrome) of known weight that was then connected to a gas analyzer and degassed at $150{ }^{\circ} \mathrm{C}$ and $1.0 \times 10^{-5}$ bar for $10 \mathrm{~h}$. The degassed sample was refilled, weighed precisely, and then transferred back to the analyzer. The temperatures for adsorption measurements were controlled using a refrigerated bath of liquid nitrogen $(77 \mathrm{~K})$ for $\mathrm{N}_{2}$ and a temperature-controlled water bath (273 $\mathrm{K})$ for $\mathrm{CO}_{2}$. The surface electronic states were investigated by X-ray photoelectron spectroscopy (XPS; Thermo VG ESCALAB250 using $\mathrm{Al} \mathrm{K} \alpha$ radiation). The XPS data were internally calibrated, fixing the binding energy of C $1 \mathrm{~s}$ at $284.6 \mathrm{eV}$. Thermogravimetric analysis was carried out on a TGA Q5000 apparatus from TA Instruments.

CO Catalytic Oxidation. For oxidation experiments, the catalyst $(25 \mathrm{mg})$ was placed inside a Thermolyne 2100 programmable tube furnace reactor (Figure S5, Supporting Information). ${ }^{24-26}$ The sample temperature was measured with a thermocouple placed near the sample. In a typical experiment, a gas mixture consisting of $4 \mathrm{wt} \% \mathrm{CO}$ and 20 wt $\% \mathrm{O}_{2}$ in helium was passed over the sample as the temperature was ramped. The gas mixture was set to flow over the sample at a rate of $100 \mathrm{~cm}^{3} / \mathrm{min}$ controlled by MKS digital flow meters. The conversion of $\mathrm{CO}$ to $\mathrm{CO}_{2}$ was monitored using an infrared gas analyzer (ACS, Automated Custom Systems Inc.). All catalytic activities were measured after heat treatment of the catalyst at $110^{\circ} \mathrm{C}$ in the reactant gas mixture for $15 \mathrm{~min}$ to remove moisture and adsorbed impurities.

\section{ASSOCIATED CONTENT}

\section{Supporting Information}

The Supporting Information is available free of charge on the ACS Publication Web site at The Supporting Information is available free of charge on the ACS Publications website at DOI: 10.1021 /acsami.7b03555.

Carbon 1s XPS spectra of Ce-MOF and 5 wt \% Pd/CeMOF; pore size distributions of 5 wt $\% \mathrm{Pd} / \mathrm{Ce}-\mathrm{MOF}$ calculated using the $\mathrm{N}_{2}$ and $\mathrm{CO}_{2}$ adsorption isotherms at $77 \mathrm{~K}$; comparison of $\mathrm{CO}$ oxidations on $5 \mathrm{wt} \% \mathrm{Pd} / \mathrm{Ce}-$ MOF, 5 wt \% Au/Ce-MOF, and 5 wt \% Pt/Ce-MOF; $\mathrm{CO}$ oxidation on 5 wt \% $\mathrm{Pd} / \mathrm{Ce}-\mathrm{MOF}$ as a function of time at $90{ }^{\circ} \mathrm{C}$ for $8 \mathrm{~h}$; and experimental setup for the catalytic oxidation of $\mathrm{CO}$ (PDF)

\section{AUTHOR INFORMATION}

\section{Corresponding Author}

*E-mail: mselshal@vcu.edu.

ORCID

M. Samy El-Shall: 0000-0002-1013-4948 


\section{Notes}

The authors declare no competing financial interest.

\section{ACKNOWLEDGMENTS}

We thank the National Science Foundation (CHE-1463989 and IIA-1445489) for support of this work. This work was also partially supported by the Center for Rational Catalysis Synthesis (CeRCas) supported by the National Science Foundation at the University of South Carolina and Virginia Commonwealth University.

\section{REFERENCES}

(1) O’Keeffe, M.; Yaghi, O. M. Deconstructing the Crystal Structures of Metal-Organic Frameworks and Related Materials into Their Underlying Nets. Chem. Rev. 2012, 112, 675-702.

(2) Furukawa, H.; Cordova, K. E.; O’Keeffe, M.; Yaghi, O. M. The Chemistry and Applications of Metal-Organic Frameworks. Science 2013, 341, 974-986.

(3) Jiang, H. L.; Liu, B.; Akita, T.; Haruta, M.; Sakurai, H.; Xu, Q. Au@ZIF-8: CO Oxidation over Gold Nanoparticles Deposited to Metal-Organic Framework. J. Am. Chem. Soc. 2009, 131, 1130211303.

(4) El-Shall, M. S.; Abdelsayed, V.; Khder, A. E. R. S.; Hassan, H. M. A.; El-Kaderi, H. M.; Reich, T. E. Metallic and Bimetallic Nanocatalysts Incorporated into Highly Porous Coordination Polymer MIL101. J. Mater. Chem. 2009, 19, 7625-7631.

(5) Guo, Z.; Xiao, C.; Maligal-Ganesh, R. V.; Zhou, L.; Goh, T. W.; Li, X.; Tesfagaber, D.; Thiel, A.; Huang, W. Pt Nanoclusters Confined within Metal-Organic Framework Cavities for Chemoselective Cinnamaldehyde Hydrogenation. ACS Catal. 2014, 4, 1340-1348.

(6) Choi, K. M.; Na, K.; Somorjai, G. A.; Yaghi, O. M. Chemical Environment Control and Enhanced Catalytic Performance of Platinum Nanoparticles Embedded in Nanocrystalline Metal-Organic Frameworks. J. Am. Chem. Soc. 2015, 137, 7810-7816.

(7) Kitagawa, S.; Kitaura, R.; Noro, S. Functional Porous Coordination Polymers. Angew. Chem., Int. Ed. 2004, 43, 2334-2375.

(8) Hermes, S.; Schroter, M. K.; Schmid, R.; Khodeir, L.; Muhler, M.; Tissler, A.; Fischer, R. W.; Fischer, R. A. Metal@MOF: loading of highly porous coordination polymers host lattices by metal-organic chemical vapor deposition. Angew. Chem., Int. Ed. 2005, 44, 62376241.

(9) Perles, J.; Iglesias, M.; Martin-Luengo, M. A.; Monge, M. A.; Ruiz-Valero, C.; Snejko, N. Metal-Organic Scandium Framework: Useful Material for Hydrogen Storage and Catalysis. Chem. Mater. 2005, 17, 5837-5842.

(10) Sabo, M.; Henschel, A.; Froede, H.; Klemm, E.; Kaskel, S. Solution Infiltration of Palladium into MOF-5: Synthesis, Physisorption and Catalytic Properties. J. Mater. Chem. 2007, 17, 3827-3832.

(11) Dhakshinamoorthy, A.; Opanasenko, M.; Cejka, J.; Garcia, H. Metal-Organic Frameworks as Heterogeneous Catalysts for the Production of Fine Chemicals. Catal. Sci. Technol. 2013, 3, 25092540.

(12) Corma, A.; Garcia, H.; Llabres i Xamena, F. X. Engineering Metal-Organic Frameworks for Heterogeneous Catalysis. Chem. Rev. 2010, 110, 4606-4655.

(13) Morozan, A.; Jaouen, F. Metal-Organic Frameworks for Electrochemical Applications. Energy Environ. Sci. 2012, 5, 9269-9290.

(14) Li, S.-L.; Xu, Q. Metal-Organic Frameworks as Platforms for Clean Energy. Energy Environ. Sci. 2013, 6, 1656-1683.

(15) Fateeva, A.; Chater, P. A.; Ireland, C. P.; Tahir, A. A.; Khimyak, Y. Z.; Wiper, P. V.; Darwent, J. R.; Rosseinsky, M. J. A Water-Stable Porphyrin-Based Metal-Organic Framework Active for Visible-Light Photocatalysis. Angew. Chem., Int. Ed. 2012, 51, 7440-7444.

(16) Wang, C.; Xie, Z.; deKrafft, K. E.; Lin, W. Doping MetalOrganic Frameworks for Water Oxidation, Carbon Dioxide Reduction, and Organic Photocatalysis. J. Am. Chem. Soc. 2011, 133, 1344513454.
(17) Zou, R.-Q.; Sakurai, H.; Xu, Q. Preparation, Adsorption Properties, and Catalytic Activity of 3D Porous Metal-Organic Frameworks Composed of Cubic Building Blocks and Alkali-Metal Ions. Angew. Chem., Int. Ed. 2006, 45, 2542-2546.

(18) Zou, R.-Q.; Sakurai, H.; Han, S.; Zhong, R.-Q.; Xu, Q. Probing the Lewis Acid Sites and CO Catalytic Oxidation Activity of the Porous Metal-Organic Polymer [ $\mathrm{Cu}(5$-methylisophthalate)]. J. Am. Chem. Soc. 2007, 129, 8402-8403.

(19) Ye, J.-Y.; Liu, C.-J. $\mathrm{Cu}_{3}(\mathrm{BTC})_{2}$ : CO Oxidation Over MOF based Catalysts. Chem. Commun. 2011, 47, 2167-2169.

(20) Zhao, Y.; Zhong, C.; Liu, C.-J. Enhanced CO Oxidation over Thermal treated Ag/Cu-BTC. Catal. Commun. 2013, 38, 74-76.

(21) Qian, L.; Zhen, Z.; Jian, L.; Yue-Chang, W.; Gui-Yuan, J.; Ai-Jun, D. Pd Nanoparticles Deposited on Metal-Organic Framework of MIL-53(Al): An Active Catalyst for CO Oxidation. Acta Phys.-Chim. Sin. 2014, 30, 129-134.

(22) Green, F.; Short, S. IEH Assessment on Indoor Air Quality in the Home: Carbon Monoxide; Institute for Environment and Health: Leicester, U.K., 1998.

(23) Igarashi, H.; Fujino, T.; Watanabe, M. Hydrogen ElectroOxidation on Platinum Catalysts in the Presence of Trace Carbon Monoxide. J. Electroanal. Chem. 1995, 391, 119-123.

(24) Glaspell, G.; Hassan, H. M. A.; Elzatahry, A.; Abdalsayed, V.; ElShall, M. S. Nanocatalysis on Supported Oxides for CO Oxidation. Top. Top. Catal. 2008, 47, 22-31.

(25) Yang, Y. L.; Saoud, K. M.; Abdelsayed, V.; Glaspell, G.; Deevi, S.; El-Shall, M. S. Vapor Phase Synthesis of Supported Pd, Au, and Unsupported Bimetallic Nanoparticle Catalysts for CO Oxidation. Catal. Commun. 2006, 7, 281-284.

(26) Glaspell, G.; Hassan, H. M. A.; Elzatahry, A.; Fuoco, L.; Radwan, N. R. E.; El-Shall, M. S. Nanocatalysis on Tailored Shape Supports: Au and Pd Nanoparticles Supported on $\mathrm{MgO}$ Nanocubes and $\mathrm{ZnO}$ Nanobelts. J. Phys. Chem. B 2006, 110, 21387-2193.

(27) Almáši, M.; Zelenak, V.; Opanasenko, M.; Cisarova, I. Ce(III) and $\mathrm{Lu}(\mathrm{III})$ Metal-Organic Frameworks with Lewis Acid Metal Sites: Preparation, Sorption Properties and Catalytic Activity in Knoevenagel Condensation. Catal. Today 2015, 243, 184-194.

(28) Jhung, S. H.; Lee, J.; Yoon, J. W.; Serre, C.; Férey, G.; Chang, J. Microwave Synthesis of Chromium Terephthalate MIL-101 and Its Benzene Sorption Ability. Adv. Mater. 2007, 19, 121-124.

(29) Ibrahim, A. A.; Lin, A.; Zhang, F.; Abouzeid, K. M.; El-Shall, M. S. Palladium Nanoparticles Supported on a Metal-Organic Framework-Partially Reduced Graphene Oxide Hybrid for the Catalytic Hydrodeoxygenation of Vanillin as a Model for Biofuel Upgrade Reactions. ChemCatChem 2017, 9, 469-480.

(30) Khan, N. A.; Haque, M. M.; Jhung, S. H. Accelerated Syntheses of Porous Isostructural Lanthanide-Benzenetricarboxylates (LnBTC) Under Ultrasound at Room Temperature. Eur. J. Inorg. Chem. 2010, 2010 (31), 4975-4981.

(31) He, L.; Dumee, L. F.; Liu, D.; Velleman, L.; She, F.; Banos, C.; Davies, J. B.; Kong, L. Silver Nanoparticles Prepared by Gamma Irradiation across Metal-Organic Framework Templates. RSC Adv. 2015, 5, 10707-10715.

(32) Zhang, F.; Wang, P.; Koberstein, J.; Khalid, S.; Chan, S.-W. Cerium Oxidation State in Ceria Nanoparticles Studied with X-ray Photoelectron Spectroscopy and Absorption Near Edge Spectroscopy. Surf. Sci. 2004, 563, 74-82.

(33) Kar, S.; Patel, C.; Santra, S. Direct Room Temperature Synthesis of Valence State Engineered Ultra-Small Ceria Nanoparticles: Investigation on the Role of Ethylenediamine as a Capping Agent. J. Phys. Chem. C 2009, 113, 4862-4867.

(34) Sutradhar, N.; Sinhamahapatra, A.; Pahari, S.; Jayachandran, M.; Subramanian, B.; Bajaj, H. C.; Panda, A. B. Facile Low-Temperature Synthesis of Ceria and Samarium-Doped Ceria Nanoparticles and Catalytic Allylic Oxidation of Cyclohexene. J. Phys. Chem. C 2011, 115, $7628-7637$.

(35) Adhikari, A. K.; Lin, K.-S. Improving $\mathrm{CO}_{2}$ Adsorption Capacities and $\mathrm{CO}_{2} / \mathrm{N}_{2}$ Separation Efficiencies of MOF-74(Ni, Co) by Doping 
Palladium-containing Activated Carbon. Chem. Eng. J. 2016, 284, $1348-1360$.

(36) Cheon, Y. E.; Suh, M. P. Enhanced Hydrogen Storage by Palladium Nanoparticles Fabricated in a Redox-Active Metal-Organic Framework. Angew. Chem., Int. Ed. 2009, 48, 2899-2903.

(37) Mishra, A. K.; Ramaprabhu, S. Palladium Nanoparticles Decorated Graphite Nanoplatelets for Room Temperature Carbon Dioxide Adsorption. Chem. Eng. J. 2012, 187, 10-15.

(38) Moon, S.-Y.; Bae, J.-S.; Jeon, E.; Park, J.-W. Organic Sol-Gel Synthesis: Solution-Processable Microporous Organic Networks. Angew. Chem., Int. Ed. 2010, 49, 9504-9508.

(39) Kaur, P.; Hupp, J. H.; Nguyen, S. T. Porous Organic Polymers in Catalysis: Opportunities and Challenges. ACS Catal. 2011, 1, 819835.

(40) Lin, A.; Ibrahim, A. A.; El-Shall, M. S. Gold and Platinum Nanoparticles Incorporated within Ce-Metal-Organic Framework for CO Oxidation. Unpublished results

(41) Kim, T.; Kim, D. H.; Kim, S.; Kim, Y. D.; Bae, Y.-S.; Lee, C. Y. Low-Temperature CO Oxidation Using a Metal-Organic Framework with Unsaturated $\mathrm{Co}^{2+}$. Polyhedron 2015, 90, 18-22.

(42) Zamaro, J. M.; Perez, N. C.; Miro, E. E.; Casado, C.; Seoane, B.; Tellez, C.; Coronas, J. HKUST-1 MOF: A Matrix to Synthesize CuO and $\mathrm{CuO}-\mathrm{CeO}_{2}$ Nanoparticle Catalysts for CO Oxidation. Chem. Eng. J. 2012, 195-196, 180-187.

(43) Rao, K. N.; Bharali, P.; Thrimurthulu, G.; Reddy, B. M. Supported Copper-Ceria Catalysts for Low Temperature CO Oxidation. Catal. Commun. 2010, 11, 863-866.

(44) Mai, H.; Zhang, D.; Shi, L.; Yan, T.; Li, H. Highly Active $\mathrm{Ce}_{1-\mathrm{x}} \mathrm{Cu}_{\mathrm{x}} \mathrm{O}_{2}$ Nanocomposite Catalysts for the Low Temperature Oxidation of CO. Appl. Surf. Sci. 2011, 257, 7551-7559.

(45) Liu, B.; Liu, J.; Li, T.; Zhao, Z.; Gong, X.-Q.; Chen, Y.; Duan, A.; Jiang, G.; Wei, Y. Interfacial Effects of $\mathrm{CeO}_{2}$-Supported Pd Nanorod in Catalytic CO Oxidation: A Theoretical Study. J. Phys. Chem. C 2015, 119, 12923-12934. 